benefit from the operation, as shown in the more rapid local and constitutional improvement and the greater ease with which the parts are cleansed. It is useless to cite cases, as all tell practically the same story. $\mathrm{My}$ private patients have possibly given the better results, as they have continued treatment a longer time and have been more thorough in their part of it.

In the rare instances in which the process has run its course with complete destruction of the turbinal tissue and cessation of abnormal secretion and crusts it is probably wise to let well enough alone. I have seen not more than a half dozen such cases.

In going over more than 3,000 cases $I$ find that deflected septa, with or without spurs and ridges, are almost invariably associated with loss of turbinal tissue; that in true atrophy it is the rule to find one fossa more roomy than the other and the atrophic process more advanced on the roomy side. The ages range from 3 years to 79 . Occupation seems to have little influence in etiology, but good air hastens recovery as much as in any other condition. About 67 per cent. are women in my collection of cases. This percentage is doubtless too large, and means that women are more apt than men to seek relief when suffering from the condition.

Let me urge for the good of society at large the thorough treatment of atrophic cases and that the operative side be not neglected.

\section{THE DISTRIBUTION OF BLOOD VESSELS IN THE LABYRINTH OF THE SAR.*}

GEORGE E. SHAMBAUGH, M.D.

Instructor In Anatomy of the Ear, Nose and Throat, University of Chicago; Associate in Otology, Rush Medical College. CHICAgo.

The course of the blood stream through the labyrinth of the ear has been a subject of considerable uncertainty and difference of opinion among anatomists. The reasons are obvious, for the complicated series of cavities that go to make up the labyrinth of the ear makes the study of the blood supply by the ordinary method from sections very inaccurate, unless laborious methods of reconstruction are used. This element of difficulty was successfully overcome, however, when Eichler introduced the method of making celloidin casts of the labyrinth in which the circulation could be viewed in its entirety. But with this accomplished, and with such a complete picture of the blood supply before one, the complicated network of vessels found in the labyrinth of the adult ear is, in many places, very difficult if not quite impossible to disentangke with any degree of accuracy.

The arteries offer the chief difficulty, for in the fullydeveloped ear these vessels undergo a remarkable series of windings and convolutions which have been designated by Schwalbe as "glomeruli." It was found, however, that in the younger stages of the embryo the arteries are perfectly straight and simple, as are the veins. In this work the circulation in the labvrinth of the ear has been worked out, using the simpler scheme found in the younger embryos to interpret, when necessary, the more complicated system found in the adult.

The material used was the embryo pig. An unlimited supply of fresh material gave ample opportunity for

* Read at the Fifty-fourth Annual Session of the American Medical Association, in the Section on Laryngology and Otology, and approved for publication by the Executive Conmittee: Drs. George L. Richards, O. Joachim and G. V. Woollen. The detalled report of this research, from the Laboratory of Anatomy, University cations of the University of Chicago. experimenting with methods of injection until satisfactory preparations could be obtained in sufficient numbers for study. An aqueous solution of Prussian blue was used as injecting medium. This penetrates readily the capillaries, and with this fluid it is possible to get complete injection of the arteries, veins and capillaries. The differentiation between arteries, veins and capillaries in these preparations where but one injection was used, ean be made out by carefully studying the preparations.

The method chiefly used in this work was that introduced by Oswald Eichler of making celloidin casts of the labyrinth from preparations that have been previously injected. Among the large series of preparations made were a few where the arterial tree alone was injected and several where the venous tree alone was filled. In most of the preparations both the arteries and the veins were filled as well as the oapillaries. In addition to the celloidin casts, thick sections were made of the injected decalcified labyrinth in order to verify certain points about which there was an element of doubt from the study of the casts.

The results of the work can be expressed briefly as follows :

1. But one artery, the labyrinthine, supplies the labyrinth in the ear of the pig. 'This vessel enters the labyrinth along with the auditory nerve through the meatus acusticus internus. A single vein, the vena canaliculi cochlex, drains the labyrinth, leaving, along with the canaliculus cochlex, at a point distinct from that at which the artery enters.

2. The several divisions of the labyrinthine artery which go to supply the cochlea anastomose frecly with each other through a number of anastomotic loops or arcades at the base of the cochlea, thus insuring for each part a blood supply reinforced freely from each division.

3. The arterial supply to the cochlea is arranged on such a plan that, as a rule, the vessels which send out the arteries to supply the scala vestibuli of a coil send out another set of arteries which supply the lamina spiralis of the coil next above. The arrangement usually described for the human ear, where the arteries for the scala vestibuli and for the lamina spiralis of the same coil comes from the same vessel, is found in the cochlea of the pig's ear, but only as the exception.

4. The venous blood of the cochlea drains entirely into the vena canaliculi cochleæ. The veins from the ligamentum spirale of the first half of the basal coil are collected into a large trunk which runs along the middle of the under surface of the basal coil to empty into the vena canaliculi cochleæ. The veins from the remainder of the basal coil are collected into the posterior spiral vein which runs along the posterior inner margin of the coil.

5 . The venous blood from the upper coils of the cochlea is collected by a tributary of the posterior spiral vein. This vein in its beginning follows the spiral direction of the upper coil. It then passes directly downward through the modiolus to join the posterior spiral vein, receiving tributaries from the upper coils which converge toward this central vessel. The anterior spiral vein which Siebenmann found in the cochlea of the human ear does not exist in the ear of the pig.

6 . The veins which lie between the coils of the cochlea are supplied by two sets of tributaries, one of which collects the blood from the scala vestibuli of the coil 
beneath, and the other from the scala tympani of the coil above.

7. The so-called spiral veins of the cochlea, which are usually described running under the tunnel of corti, in the crista spiralis, in the crista of the ligamentum spirale and in the prominentia spiralis, are formed in the ear of the pig from capillary loops which form the boundary line for distinct capillary areas in these parts.

8. There was often found in the cochlea of the pig's ear a connection between the vessels of the lamina spiralis and those of the ligamentum spiralc. This connecting link consisted of straight veins which ran from the terminal loops under the tunnel of Corti across to the veins in the crista of the ligamentum spirale, and were found in the terminal coil as well as in the basal coil.

9. The arterial supply for the vestibule and the semicircular canals comes in part from the anterior vestibular artery, and in part from arteries which spring from the anastomotic loops between the arterial trunks which supply the cochlea.

10. The venous blood from the vestibule and the semicircular canals is collected into two large trunks which empty into the vena canaliculi cochleæ. This is in striking contrast to the condition found by Siebenmann and Eichler in the human ear, where the veins from the semicircular canals left the labyrinth with the aqueductus vestibuli.

11. The capillaries are distributed almost exclusively to the membranous labyrinth. In the semicircular canals this is shown the most clearly. Here the capillaries surround the membranous canal while the rein runs along its inner concave surface, and the artery, for the most part, clings to the inner concave surface of the osseus canal, sending an occasional twig to the capillary loops around the membranous tube.

12. The capillary loops of the membranous semicircular canals do not, as a rule, completely surround this tube, but leave a zone along its convex surface free from vessels except for an occasional connecting loop which runs across this space.

\section{PROFESSIONAL RESPONSIBILITIES.*}

\section{A. E. BALDWIN, M.D., D.D.S., LL.B. ChICAgo.}

While this is a hackneyed subject, it is one on which we ought to devote a great deal of thought. We stand before the public and the general profession as the guardians of the entrance to the alimentary canal, and these responsibilities laid on us determine many things in connection with the general health of our patrons. I am not unmindful that while we occupy a very limited field as to the actual work which we do, the far-reaching effect of the work, or lack of it, is easily demonstrable. It seems to me that we fall short of a just and broad comprehension of our responsibilities in many instances.

These responsibilities begin in our advising our patrons as to the care and carefulness with which the temporary teeth of the little ones should be protected, as well as advising as to the care of the permanent teeth which obtain in later years.

In former papers before this and other gatherings I have urged on the general profession as well as on our

- Read at the Fifty-fourth Annual Session of the American Medical Association, in the Section on Stomatology, and approved for publication by the Executive Committee: Drs. M. L. Rhein, II. I. Fletcher and Wm. F. Walker. spccial department the care which should be bestowed on the deciduous tecth. It doubtless is overlooked by many general practitioners and, judging from my observation, by even many in our special field that the teeth of the growing child should be kept more carefully even than the teeth of the adult. A reason apparent to all is that while in adult life nutrition is necessary only to make up for the waste of tissues, in the growing child there are many reasons why added nutrition should be obtained, chief among which may be mentioned the waste tissues which must be made up are fully as large in proportion as in the adult, while with the child there is a rapid development of the general system requiring much additional nutriment. Indirectly, there are many' other reasons, among which are these: A child has a vigorous and almost unlimited appetite; if these deciduous molar teeth are allowed to become sensitive, painful or lost, the mastication of the child is necessarily hampered, and it is an axiom that a child will never masticate food if by so doing pain is caused. They very early in life learn that despicable habit of "bolting" their food with but little or no mastication, if mastication is in any way disagreeable, thus fixing on them a habit for life which is conducive to many of the ills of indigestion and malnutrition. A still further reason is the fact that all teeth in the mouth at all ages have a tendency to move toward the median line of the mouth, hence if one of these deciduous teeth is extracted before its successor is ready to crupt, the teeth behind will move toward the front, thus preventing the proper eruption and corresponding development and expansion of the arch, and causing the coming in of the teeth in abnormal positions, and creating irregularity and its subsequent ills.

I have always urged on the general profession and our special department that exceeding care should be given to the deciduous molar teeth, and that we should advise our patrons to urge on the child a thorough use of the brush. There should be frequent inspections of these teeth, and whenever a suspicion of decay invades them immediate professional attention should be given. If they are preserved in a healthful condition, mastication can be performed fully, so that the ills resulting from "bolting" of food may not invade the stomach of the little patient, bringing on it the ills of indigestion. We frequently recognize that in the case of a very nervous little one the only trouble, probably, is dyspepsia caused by lack of the above attentions, so that I would urge on the members of our specialty that most careful attention be given to these teeth until the time for them to be replaced by the permanent bicuspids, as well as that very great care should be observed in attention to the first permanent molar which is erupted at about the sixth year of age, and the molars which are subsequently erupted posteriorly thereto.

This first permanent molar we all recognize is the abutment of the arch, and is from its location, position, size and attachments, the most important tooth of the mouth to be preserved at this or any subsequent period. The loss of this tooth, or lack of attention thereto, as well as the lack of care of the deciduous molars, in my belief, produces most of these cases of irregularities and deformities of the lower part of the face, Nature having evidently intended that the lower part of the face should be developed and expansion thereto attained by the gradual wedging in and pushing apart of the alveolar process by the eruption of the larger teeth of the permanent set. 